\title{
Guideline for office spirometry in adults, 2012
}

\author{
C F N Koegelenberg, F Swart, E M Irusen \\ Division of Pulmonology, Department of Medicine, University of Stellenbosch and Tygerberg Academic Hospital, Cape Town \\ C F N Koegelenberg, MB ChB, MMed (Int), FCP (SA), MRCP (UK), Cert Pulm (SA), PhD \\ F Swart, NDClinTech (SA) \\ E M Irusen, MB ChB, FCP (SA), PhD
}

Corresponding author: C F N Koegelenberg (coeniefn@sun.ac.za)

Background. Office spirometry remains an integral part of a comprehensive respiratory evaluation and is used to categorise the nature, severity and progression of respiratory diseases and to measure response to treatment. These updated guidelines are aimed at improving the quality, standardisation and usefulness of office spirometry in South Africa.

Recommendations. All equipment should have proof of validation regarding resolution and the system's linearity (consistency). Moreover, equipment must be calibrated daily and quality controlled. It is also important to have standard operating procedures in place, including the documentation of ambient conditions and infection control measures.

Adequate spirometry relies on a competent operator, accurate equipment, standardised operating procedures, quality control and patient co-operation. The indication for spirometry in a particular patient should be unambiguous and should be documented. Subjects should be appropriately prepared for testing, and patient details must be documented. Forced vital capacity (FVC) manoeuvres (either closed or open circuit) must be performed strictly according to guidelines, and strict quality assurance methods should be in place, including acceptability criteria (for any given effort) and repeatability (between efforts). Testing should continue until at least 3 acceptable curves are produced (with 2 fulfilling repeatability criteria). Other indices are derived from these efforts.

Conclusion. Test results must be categorised and graded according to current guidelines, taking into account the indication for the test and the appropriateness of reference values.

S Afr Med J 2013;103(1):52-61. DOI:10.7196/SAMJ.6197

\section{Introduction}

Pulmonary function testing is used to categorise the nature, severity and progression of respiratory disorders and to measure the patient's response to therapy. Office spirometry remains an integral part of a comprehensive respiratory evaluation and is often used as an adjunct to the diagnosis of asthma and chronic obstructive pulmonary disease (COPD) and to screen for occupational lung diseases. ${ }^{1,2}$ However, improper standards and operating procedures significantly reduce its value in the diagnosis of and screening for these conditions. ${ }^{1,2}$

Adequate spirometry relies on a competent operator, accurate equipment, standardised operating procedures ( $\mathrm{SOPs}$ ), quality control and patient co-operation. ${ }^{2,3}$ Moreover, appropriate and validated reference standards must be used. ${ }^{2,3}$ Spirometry should always be viewed within the clinical context, and not as a stand-alone investigation. ${ }^{3}$

The most recent South African guideline for office spirometry in $2004^{2}$ has been superseded by comprehensive international guidelines. ${ }^{3-6}$ Furthermore, there is a growing body of evidence regarding local reference standards. ${ }^{7-11}$ This article aims to provide an updated and simplified guideline for the use of office spirometry at the primary healthcare level.

\section{Basic equipment and definitions 2.1 Spirometry}

Spirometry involves the measurement of the air volumes and airflow rates of the lung. These are dependent on the physical properties of the airways, lung parenchyma, pleura and chest wall and the strength of respiratory muscles. ${ }^{1,2}$ Practically all modern commercially available computerised spirometers are flow-type spirometers that use a flow-sensor (pneumotach) to derive volumes. ${ }^{2}$ They can display expiratory and inspiratory manoeuvres in real time as flow-volume loops, allowing instant pattern recognition.

Standard features of modern spirometers include software for the storage of large data sets and the ability to express measured values as percentage predicted, using various reference value sets as a guide. These spirometers generally require greater expertise to operate, calibrate and maintain than the older volume-type spirometers, which measured volume directly and produced volume-time curves.

Spirograms (Fig. 1) are graphic displays produced by spirometers, and include volume-time curves (from both types of spirometers) and flow-volume curves (from newer flow-type spirometers). Modern equipment also automatically superimposes measured spirograms onto predicted curves.

\subsection{Measurements}

The minimum measurements that basic office spirometers should produce include:

- Forced vital capacity (FVC): The maximum volume of gas exhaled from the position of maximal inspiration by means of a rapid, maximally forced expiratory effort, expressed in litres (body temperature and ambient pressure, saturated with water vapour) (BTPS). BTPS refers to a standardised volume at normal body temperature $\left(37^{\circ} \mathrm{C}\right)$ at ambient pressure, saturated with water vapour.

- Forced expiratory volume $(\mathrm{FEV})_{1}$ : The volume of gas exhaled during the first second of the FVC manoeuvre, expressed in litres (BTPS). 


\section{GUIDELINE}

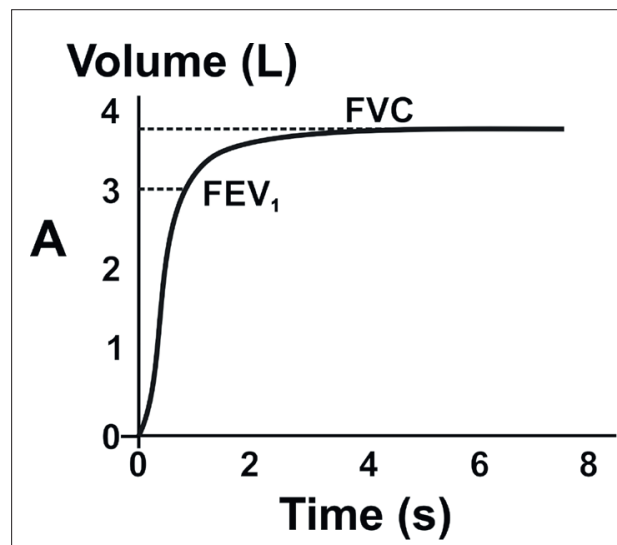

\section{Flow (L/s)}

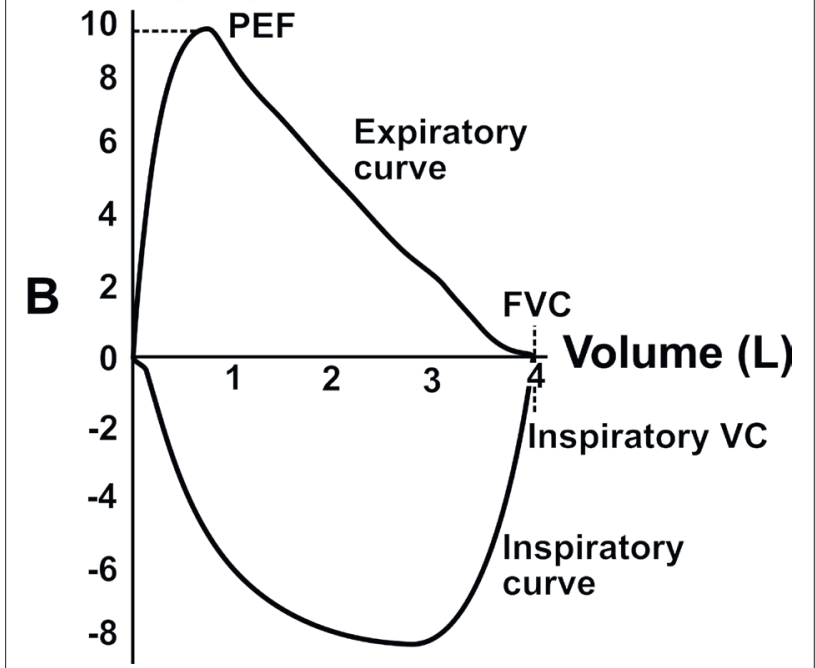

Fig. 1. A: volume-time, and B: flow-volume curves. In the flow-type spirometer, $F E V_{1}$ is a derived value. It can only be read from the flow-volume graph if a 1-second timer is displayed. Figure adapted from Van Schalkwyk et al. ${ }^{2}$

- $\mathrm{FEV}_{1} / \mathrm{FVC} \%$ : The observed $\mathrm{FEV}_{1}$ expressed as the percentage of observed FVC $\left(\mathrm{FEV}_{1} / \mathrm{FVC} \times 100\right)$

- Peak expiratory flow (PEF): The maximum flow generated with an FVC manoeuvre, usually expressed in litres per second (BTPS).

Additional measurements may include:

- Vital capacity (VC): The 'slow' VC (sometimes referred to as SVC) is the total volume of gas inhaled from the position of maximal expiration or exhaled from the position of maximal inspiration. It is measured with a relaxed/ slow breathing manoeuvre either during inspiration or expiration. VC is expressed in litres (BTPS), and may be useful for demonstrating small airway collapse in COPD patients.

- $\mathrm{FEV}_{\mathrm{X}}$ : The volume of gas exhaled during the first $\mathrm{X}$ seconds of the FVC manoeuvre, expressed in litres (BTPS), e.g. $\mathrm{FEV}_{6}$.

- $\mathrm{FEF}_{\mathrm{X} \%}$ : The instantaneous forced expiratory flow rate at the point where $\mathrm{X} \%$ of the $\mathrm{FVC}$ has been expired, e.g. at $25 \%, 50 \%$ and $75 \%\left(\mathrm{FEF}_{25 \%}, \mathrm{FEF}_{50 \%}\right.$ and $\left.\mathrm{FEF}_{75 \%}\right)$. These measurements are expressed in litres per second (BTPS).

- $\mathrm{FEF}_{25-75 \%}$ : Average flow during the middle $50 \%$ of an FVC manoeuvre, also sometimes referred to as the maximum midexpiratory flow. Expressed in litres per second (BTPS).

\subsection{Accuracy, repeatability and reproducibility}

Accuracy is the truthfulness or closeness of agreement between the result of a measurement and the true value. ${ }^{3}$

Repeatability is the closeness of agreement (precision) between the results of successive measurements of the same patient (provided that the same methods, instrument, observer and conditions are present for thesem measurements).

Reproducibility is the closeness of agreement of the results of successive measurements of the same item where the measurements are carried out with changed conditions (e.g. methods, observer, instrument, location, conditions of use, or time). ${ }^{3}$

\subsection{Measurement range and equipment resolution}

The measurement range is the range over which the manufacturer indicates that the device complies with the equipment resolution, which is the smallest detectable change in measurement. ${ }^{3}$

\subsection{Calibration and validation}

Calibration is the process whereby a device's accuracy and repeatability are tested and corrected using a gold standard, e.g. a calibration syringe with standard volumes. Validation is the process of establishing and certifying that the device is correctly calibrated.

\section{Indications for spirometry}

The indications for spirometry in a particular patient should be unambiguous and should be documented in each case. Indications include: ${ }^{2,4}$

- Diagnostic

- evaluating abnormal respiratory symptoms and signs (in individuals with suspected obstructive and/or restrictive lung diseases)

- measuring the extent to which a disease affects the respiratory system

- screening individuals at risk, e.g. smokers, employees exposed to substances known to cause respiratory disease

- preoperative risk assessment

- assessing prognosis

- Monitoring

- assessing interventions/treatment action plan

- monitoring the course of chronic lung diseases

- monitoring patients exposed to injurious agents

- screening for pulmonary toxicity secondary to drugs

- Evaluation of impairment

- insurance and disability

- rehabilitation

- medico-legal cases

- Public health

- epidemiological surveys and derivation of reference equations.

\section{Specifications and technical preparation for spirometry}

\subsection{Validation}

All equipment should have proof of validation. ${ }^{2,4}$ Accuracy depends on the system's resolution (minimum detectable volume or flow) and linearity (consistency), from the measuring components to the display and graphical output.

The European Respiratory Society/American Thoracic Society (ERS/ATS) Taskforce for the Standardisation of Lung Function Testing has recommended minimum performance criteria for spirometers, and guidelines for validating equipment using waveform-generated calibration syringes ${ }^{5}$ (Tables 1 and 2). Other recommendations include: 
Table 1. Selective minimum volume and flow criteria for diagnostic spirometers

\begin{tabular}{|c|c|c|c|c|c|c|}
\hline Parameter & $\begin{array}{l}\text { Volume range } \\
\text { (l) }\end{array}$ & $\begin{array}{l}\text { Accuracy } \\
\text { (BTPS) }\end{array}$ & $\begin{array}{l}\text { Repeatability }{ }^{\dagger} \\
\text { (BTPS) }\end{array}$ & $\begin{array}{l}\text { Flow range } \\
(1 / s)\end{array}$ & $\begin{array}{l}\text { Time } \\
\text { (s) }\end{array}$ & $\begin{array}{l}\text { Validation } \\
\text { method }\end{array}$ \\
\hline FVC & $0.5-8.0$ & $\begin{array}{l}+/-3 \% \text { of reading or } \\
+/-0.0501, \text { whichever is } \\
\text { greater }\end{array}$ & $\begin{array}{l}+/-4.5 \% \text { of reading or }+/-0.2001 \text {, } \\
\text { whichever is greater }\end{array}$ & $0-14$ & 30 & $\begin{array}{l}24 \text { ATS waveforms, } \\
31 \text { calibration } \\
\text { syringe }\end{array}$ \\
\hline $\mathrm{FEV}_{1}$ & $0.5-8.0$ & $\begin{array}{l}+/-3 \% \text { of reading or } \\
+/-0.0501, \text { whichever is } \\
\text { greater }\end{array}$ & $\begin{array}{l}+/-4.5 \% \text { of reading or }+/-0.2001 \text {, } \\
\text { whichever is greater }\end{array}$ & $0-14$ & 1 & 24 ATS waveforms \\
\hline PEF & NA & $\begin{array}{l}+/-10 \% \text { of reading or }+/- \\
0.301 / s, \text { whichever is } \\
\text { greater }\end{array}$ & $\begin{array}{l}+/-5 \% \text { of reading or } 0.151 / \mathrm{s} \text {, } \\
\text { whichever is greater }\end{array}$ & $0-14$ & & $\begin{array}{l}24 \text { ATS flow } \\
\text { waveforms }\end{array}$ \\
\hline
\end{tabular}

Table 2. Minimum scale for spirograms ${ }^{\star}$

\begin{tabular}{|c|c|c|c|c|}
\hline \multirow[b]{2}{*}{ Parameter } & \multicolumn{2}{|c|}{ Instrument display } & \multicolumn{2}{|c|}{ Graphical output } \\
\hline & Required resolution & Scaling & Required resolution & Scaling \\
\hline Volume & 0.0501 & $5 \mathrm{~mm} / \mathrm{l}$ & 0.0251 & $10 \mathrm{~mm} / \mathrm{l}$ \\
\hline Flow & $0.200 \mathrm{l} / \mathrm{s}$ & $2.5 \mathrm{~mm} / \mathrm{l} / \mathrm{s}$ & $0.100 \mathrm{l} / \mathrm{s}$ & $5 \mathrm{~mm} / \mathrm{l} / \mathrm{s}$ \\
\hline Time & $0.2 \mathrm{~s}$ & $10 \mathrm{~mm} / \mathrm{s}$ & $0.2 \mathrm{~s}$ & $20 \mathrm{~mm} / \mathrm{s}$ \\
\hline
\end{tabular}

- a BTPS-correction facility. The volume of exhaled gas is measured outside the body at ambient conditions, designated ambient temperature and pressure, saturated with water vapour (ATPS). This facility corrects these measurements to reflect conditions inside the lung (BTPS). Without it, volumes have to be corrected manually. Depending on the environmental temperature, the BTPS correction factor may be as large as $10 \%$. Ambient temperature, barometric pressure and time of day should therefore be recorded.

- the facility to generate real-time spirograms, in order to enhance feedback and subject compliance

- stating the source(s) of reference values, combined with the facility to select or enter appropriate values manually

- computer-driven technical quality indicators that meet ERS/ ATS standards

- printing or electronic facility for record-keeping purposes

- adequate ability to save large numbers of tests and test quality indicators where needed, e.g. for occupational surveillance.

\subsection{Calibration and equipment quality control}

To ensure that they remain accurate during use, all diagnostic spirometers must be volume-calibrated at least daily, using a calibrated syringe with a volume of at least $3 \mathrm{l}$. In some settings (e.g. industrial surveys), the calibration should be performed twice daily. Moreover, calibration should be repeated if the temperature changes markedly over the course of a day.

Flow-type spirometers should be calibrated with at least 3 discharges to give a range of flows from $0.5 \mathrm{l} / \mathrm{s}$ to $12 \mathrm{l} / \mathrm{s}$ (with the 31 syringe this equates to times of approximately $6 \mathrm{~s}$ and $<0.5 \mathrm{~s}$ ). This must be done with the machine switched to calibration mode, to prevent BTPS-correction because room air has been injected. Also enter ambient temperature and barometric pressure readings, which may be obtained from the local airport or weather bureau.
Calibration is complete when the recorded volumes are within 3.5\% for each flow rate tested. Calibration should be performed with in-line filters installed.

For linearity, a volume calibration check should be performed weekly, using a 31 syringe to deliver 3 constant flows at a low flow, followed by 3 at a mid-range flow and finally 3 at a high flow. The volumes achieved at each of these flows should meet the accuracy requirement of $+/-3.5 \%{ }^{4}$

Volume-type spirometers must be evaluated for leaks daily (with $0.3 \mathrm{kPa}$ constant pressure for 1 minute), and for volume linearity quarterly (1l increments with a calibrating syringe measured over the entire volume range). ${ }^{4}$

Further measures for equipment quality control are the installation of software updates (which should be logged), and quarterly calibration of the time clock (by mechanical recorded checks with a stopwatch). In addition to calibration, spirometers must be maintained according to the manufacturer's specifications. For example, pneumotachs must be cleaned weekly (more frequently if there is visible condensation) as they are particularly sensitive to moisture and secretions. It is advisable that the local supplier/manufacturer should also service spirometers annually.

At a minimum, a calibration and maintenance log and electronic or hard copies of whole spirograms must be kept, so that the accuracy and precision of past tests can be verified. Additionally, SOPs should be documented and kept for reference.

\subsection{Ambient conditions}

Ambient temperature, barometric pressure and time of day should be recorded daily. Temperature is a significant variable in spirometry, and may be measured directly by a simple thermometer or internal thermostat (i.e. directly by the equipment). It is the responsibility of the operator to confirm the accuracy of temperature measurements, and the manufacturer's responsibility 
to describe or provide a clear mechanism for checking the accuracy of instrument measurements. ${ }^{3}$

\section{Hygiene and infection control 5.1 Rationale}

There is a small but real risk of transmitting infections to test subjects and staff during pulmonary function testing. ${ }^{2,3}$ Practically all the components of the spirometry system have been implicated, and transmission can occur through direct and indirect contact. Upper respiratory diseases, enteric infections and blood-borne infections can be transmitted through direct contact. Hepatitis and HIV transmission becomes possibile if patients suffer from open oral mucosal ulcers or possible bleeding gums. ${ }^{2,3}$

Tuberculosis and various viral and bacterial infections can potentially be transmitted via indirect contact through aerosol droplets. Mouthpieces and the immediately proximal surfaces of valves or tubing are the most likely sources of contamination in the last two instances. The type of test manoeuvre used (and specifically whether the patient inhales from the spirometer) significantly influences the extent of infection control needed. Using an expiratory manoeuvre only, without inhalation from the spirometer, reduces the potential for cross-contamination and is the method of choice for mass screening purposes. ${ }^{2}$

\subsection{Infection control recommendations}

Transmission to operators can be prevented by proper handwashing and using barrier devices, e.g. gloves. ${ }^{3}$ Hands should be washed following direct handling of mouthpieces, tubing, valves or interior spirometer surfaces and always between patients. Operators who have open cuts or lesions on their hands should wear gloves, particularly when handling contaminated equipment.

Cross-contamination should be avoided. Mouthpieces, nose clips and any other equipment that comes into direct contact with mucosal surfaces should be disinfected, sterilised or discarded (if disposable) after each use. ${ }^{2}$ Any equipment surface (tubing, valves or manifolds) showing condensation from expired air should be disinfected or sterilised before re-use. Manufacturers' recommendations should be adhered to, particularly regarding the choice of sterilising agents, as some equipment may be damaged by chemicals or heat.

Between subjects, volume-based spirometers used with a closedcircuit technique should be flushed with room air at least 5 times over the spirometer's entire volume range to ensure clearance of droplet nuclei. The breathing tube and mouthpiece should be decontaminated or changed between patients. ${ }^{3}$

When an open circuit (either volume or flow spirometers) is used, only the portion of the circuit through which rebreathing occurs must be decontaminated between patients, as long as the subject only exhales into the spirometer. ${ }^{2,3}$

With inhalation, however, additional measures must be put in place: after each subject either in-line disposable filters must be used and replaced, or the involved parts of the system (spirometer, breathing tubes and resistive element of the pneumotach) must be decontaminated/sterilised/flushed. Most units employ in-line filters, as re-calibration is necessary every time a system has been dismantled for decontamination.

Special precautions must be taken for patients with known transmissible infections such as tuberculosis, or those with current haemoptysis. In-line filters should be used routinely (even if expiratory manoeuvres are performed exclusively), and after each use contaminated surfaces should be sterilised and equipment decontaminated. Proper attention should also be paid to environmental control, e.g. ventilation. Practical considerations include testing such cases at the end of the day (to allow overnight decontamination of equipment).

\section{Patient considerations and preparation}

The patient's gender, age, race, standing height and weight must be recorded on the day of the test, as these variables (particularly gender, race and height) are required for reference purposes. Height (and weight) should be measured with the subject barefoot (feet together), wearing only light clothing and looking straight ahead. The body mass index (kg/ $\mathrm{m}^{2}$ ) should be calculated. Smoking status and the use of any medication that can influence spirometry should be documented, including the type and dose of drugs and when they were last administered.

\subsection{Contraindications}

There are few absolute contraindications for spirometry. A major exclusion criterion in routine practice is current respiratory infections in individuals participating in impairment/disability assessment, as respiratory infections can temporarily impair lung function. ${ }^{2}$ The current ATS/ERS guideline also recommends that lung function testing should not be performed within one month of a myocardial infarction. ${ }^{3}$ Situations where suboptimal testing is likely include chest and abdominal pain, facial discomfort exacerbated by a mouthpiece, stress incontinence, dementia or an acute confusional state. ${ }^{3}$ Patients with severe emphysema who experience syncope with forced and prolonged expiration should not be retested.

\subsection{Subject preparation}

Patients should abstain from smoking (within 1 hour) and consuming alcohol (within 4 hours) of testing, and should not perform any vigorous exercise 30 minutes before testing. Clothing that restricts chest and abdominal movement and a large meal within 2 hours of testing should also be avoided. Patients should be informed of these requirements prior to testing, and deviations should be documented.

Subjects should be relaxed and comfortable before and during testing. Tight-fitting clothing should be loosened and distractions minimised. Well-fitting dentures can be left in place but loosefitting ones are best removed. The use of a nose clip is strongly recommended.

It is imperative to use simple instructions to ensure optimum co-operation, which may include real-time visual aids. Patients should be given feedback regarding their performance and continuously encouraged (including descriptions of potential improvements that can be made).

\subsection{Subject positioning}

Spirometry may be performed either sitting or standing (the position should be reported). ${ }^{12,13}$ The sitting position is the most widely used, mainly because of the risk of syncope during forced expiration. The chair should have arm rests, but no wheels. Patients with central obesity may achieve deeper inspiration while standing, and thus have higher volumes and flows when tested in this position. ${ }^{3}$

\section{Execution of tests}

\subsection{FVC and FEV test manoeuvres}

The operator should follow the summarised procedures (Table 3). The performance of an FVC manoeuvre has 3 distinct phases: (i) maximal inspiration; (ii) rapid, forceful exhalation (a 'blast'); and (iii) continued complete exhalation to the end of test (EOT). ${ }^{4}$ There are essentially two accepted procedures:

- Closed circuit method. This allows the recording of inspiration and expiration, and generation of flow-volume loops (on a flow-type spirometer). The subject assumes the correct posture, a nose clip is attached, and a mouthpiece is inserted around which the subject closes their lips. The subject 


$\begin{array}{ll}\begin{array}{l}\text { Table 3. Procedures for recording FVC } \\ \text { Verify spirometer calibration } \\ \text { Explain the procedure } \\ \text { Subject preparation }\end{array} & \begin{array}{l}\text { Enquire about medication use and } \\ \text { smoking status } \\ \text { Measure weight and height } \\ \text { Wash hands } \\ \text { Infection control }\end{array} \\ \begin{array}{ll}\text { Disposable filter } \\ \text { Correct positioning and posture } \\ \text { Complete and rapid inhalation }\end{array} \\ \text { Perform manoeuvre } & \begin{array}{l}\text { Forced, maximal exhalation } \\ \text { Closed v. open circuit (see text) } \\ \text { Repeat instructions as necessary } \\ \text { Repeat for a minimum of } 3 \text { tests }\end{array} \\ \text { Verify test quality } & \begin{array}{l}\text { Acceptability } \\ \text { Reproducibility } \\ \text { Maximum of } 8\end{array} \\ \text { Perform more attempts } & \text { Adapted from Miller et al. }\end{array}$

is instructed to inhale completely and rapidly with a pause of $<1 \mathrm{~s}$ at total lung capacity (TLC), followed by rapid, forceful and maximal exhalation until no further air can be expelled (maintaining an upright posture).

- Open circuit (expiration-only) method. This is often employed for mass screening, and consists of an FVC test with or without a slow VC test. After the subject assumes the correct posture, a clip is attached to their nose. The subject is required to inhale completely and rapidly with a pause of $<1 \mathrm{~s}$ at TLC. Thereafter a mouthpiece is inserted and the lips must be closed around it. Expiration must be rapid, forceful and complete, lasting at least 6 s. A slow VC test is sometimes performed, as a reduction in the FVC compared with the slow VC suggests dynamic collapse of airways during forced expiration. The slow VC test is preceded by a maximal inspiration, the mouthpiece is inserted and the patient then breathes out in a relaxed fashion and for as long as possible. ${ }^{2}$

\subsection{Quality assurance}

Many within-manoeuvre and between-manoeuvre criteria must be satisfied to ensure adequate quality:

- Start and end of test. The start of test ('time zero') should be determined by the back-extrapolation method (Fig. 2), and defines the start for all timed measurements., ${ }^{4,14}$ The steepest slope on the volume-time curve is used for manual measurements, whereas the largest slope averaged over an $80 \mathrm{~ms}$ period is used for computerised back-extrapolation. ${ }^{4,15}$ Current recommended EOT criteria include: (i) subjects cannot or should not continue further exhalation (due to discomfort or the risk of syncope); or (ii) the volume time curve shows no change in volume $(<0.0251$ for $\geq 1 \mathrm{~s})$; or (iii) the subject has attempted to exhale $\geq 6 \mathrm{~s}$ ( $\geq 3 \mathrm{~s}$ for children $<10$ years). ${ }^{4,5}$

- Acceptability criteria. Table 4 summarises the within-manoeuvre acceptability criteria for the recording of FVC and $\mathrm{FEV}_{1}$ Acceptable curves must satisfy all 7 criteria listed, whereas 'usable' curves only need a good start (without hesitation) and for the subject to be free of coughing during the first second (Figs 3 - 5).

- Repeatability. An adequate test requires a minimum of 3 acceptable FVC manoeuvres. Acceptable repeatability is achieved

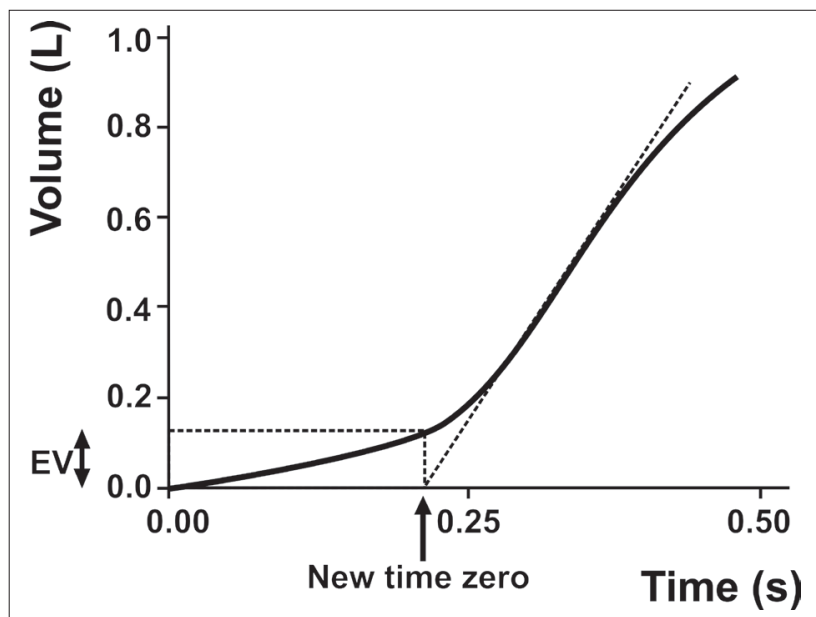

Fig. 2. Expanded version of the early part of a subject's volume-time spirogram, illustrating back-extrapolation through the steepest part of the curve, where flow is peak expiratory flow (PEF), to determine the new 'time zero'. Forced vital capacity $(F V C)=4.255$ l, back-extrapolated volume $(E V)$ $=0.128$ l (3.0\% FVC). ---- = back-extrapolation line through PEF. Figure adapted from Miller et al. ${ }^{4}$

when the difference between the largest and the next largest FVC and $\mathrm{FEV}_{1}$ is $\leq 0.150 \mathrm{l}$ (Fig. 6). ${ }^{4,16}$ For patients with a VC of 1.01 , this value is 0.1001 . If these criteria are not met after 3 attempts, additional testing should be performed, up to a maximum of 8 manoeuvres, or until the subject cannot or should not continue, or it is obvious that perseverance will not change the outcome. ${ }^{4}$ When repeatability is not achieved, results are labelled as such.

\subsection{Test result selection}

The FVC and $\mathrm{FEV}_{1}$ should be measured from a series of at least 3 acceptable forced expiratory curves. The largest FVC and the largest $\mathrm{FEV}_{1}$ (BTPS) should be recorded and used to determine other indices, even if they do not come from the same attempt.

\subsection{Other derived indices}

The PEF is obtained from flow-volume curve data, and should be reported. It is the maximum expiratory flow achieved from a maximum forced expiration, starting without hesitation from the point of maximal lung inflation, expressed in $1 / \mathrm{s} .{ }^{4} \mathrm{PEF}$ should be achieved within the first $25 \%$ of the volume expired from maximum inspiration (most subjects can produce PEF within the first $15 \%$ of the volume expired.)

The $\mathbf{F E F}_{25-75 \%}$ is also known as the maximum mid-expiratory flow, and has to be measured with an accuracy of at least $+/-5 \%$ of the reading or $+/-0.200 \mathrm{l} / \mathrm{s}$, whichever is less, over a range of up to 7 $1 / \mathrm{s}{ }^{4}$ It is dependent on the validity of the FVC measurement and the degree of expiratory effort. ${ }^{4}$

\subsection{Flow volume loops}

In most laboratories, flow volume loops are generated in real-time during FVC and FEV test manoeuvres. There are two acceptable approaches:

- The subject performs tidal breathing at FRC, and then, in one continuous sequence, performs a slow expiration to residual volume, followed immediately by a slow inspiration to TLC, and a rapid full expiration with maximal effort to RV (during which time FVC and FEV 1 are measured). This is immediately followed by a rapid full inspiration with maximum effort back to TLC. ${ }^{4}$ Both VC as well as FVC can be measured with this technique. 


\section{GUIDELINE}

Table 4. Within-manoeuvre acceptability criteria for the recording of $\mathrm{FVC}$ and $\mathrm{FEV}_{1}$

\begin{tabular}{ll}
\hline No artefacts & $\begin{array}{l}\text { Coughing during first second of expiration } \\
\text { Glottis closure (Valsalva manoeuvre) or hesitation }\end{array}$ \\
& Early termination or submaximal effort \\
& Leakage \\
& Obstructed mouthpiece \\
Good starts & $\begin{array}{l}\text { Extrapolated volume }<5 \% \text { of FVC or } 0.1501 \\
\text { (whichever is greater) }\end{array}$ \\
Exhalation & $\begin{array}{l}\text { At least } 6 \mathrm{~s} \text { (less only if the subject cannot or should } \\
\text { not continue) }\end{array}$ \\
& *Adapted from Miller et al. ${ }^{4}$
\end{tabular}

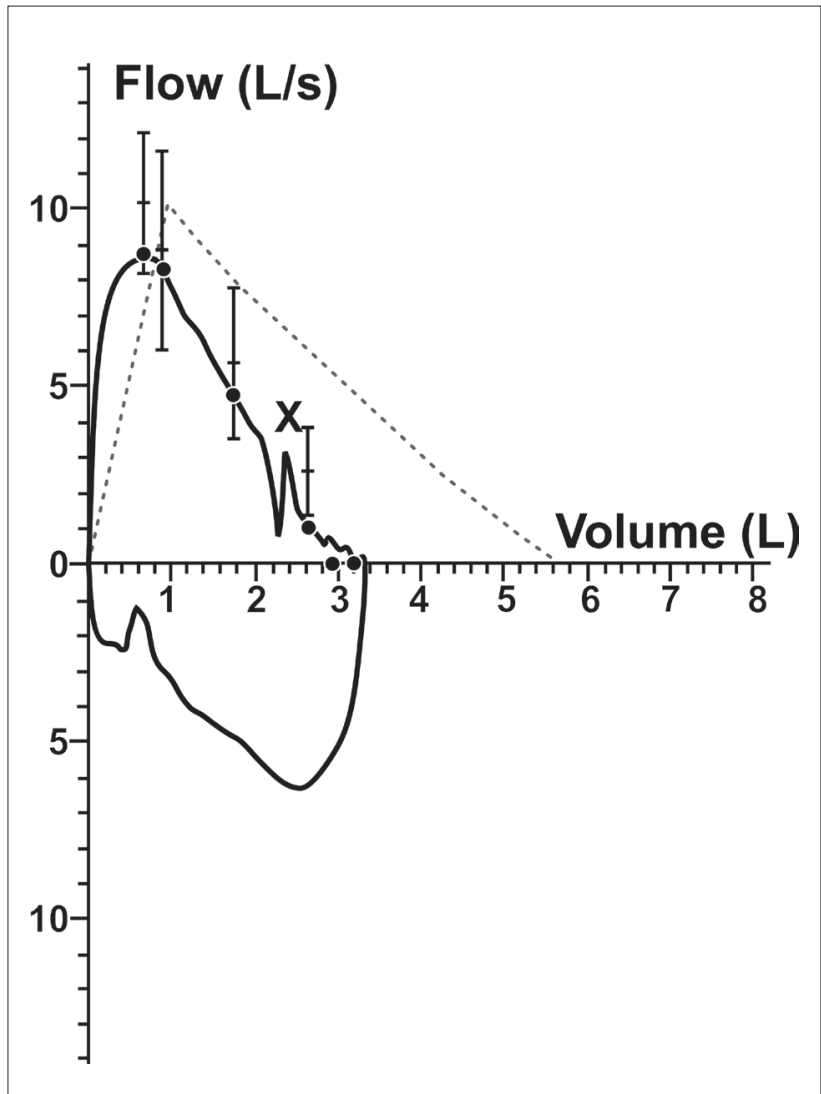

Fig. 3. Flow-volume curve exhibiting a cough artefact $(X)$ that can influence observed forced vital capacity and FEV $V_{1}$. Volume-time graphs are better for evaluating end-of-test quality.

- The subject takes a rapid full inspiration to TLC from room air through the mouth, thereafter a mouthpiece is inserted and then, without hesitation, an expiration with maximum force is performed until no more air can be expelled, followed by rapid maximum inspiration. ${ }^{4}$

The principles for within- and between-manoeuvre evaluation are the same as for FVC.

\subsection{Reversibility testing}

The purpose of a bronchodilator test is to determine whether airway obstruction, as measured by spirometry, is reversible with an inhaled bronchodilator (the choice of drug, dose and delivery mode is a

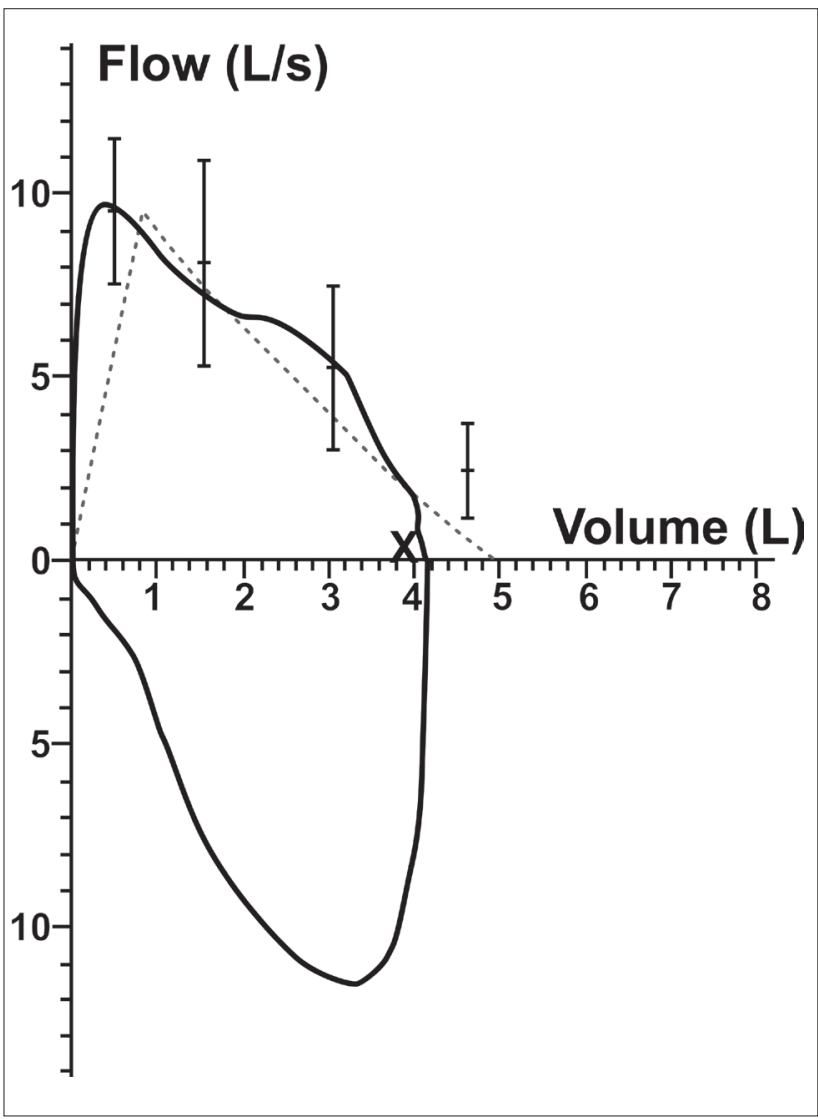

Fig. 4. Flow-volume curve exhibiting glottis closure (X) resulting in premature termination of effort and reduced observed forced vital capacity.

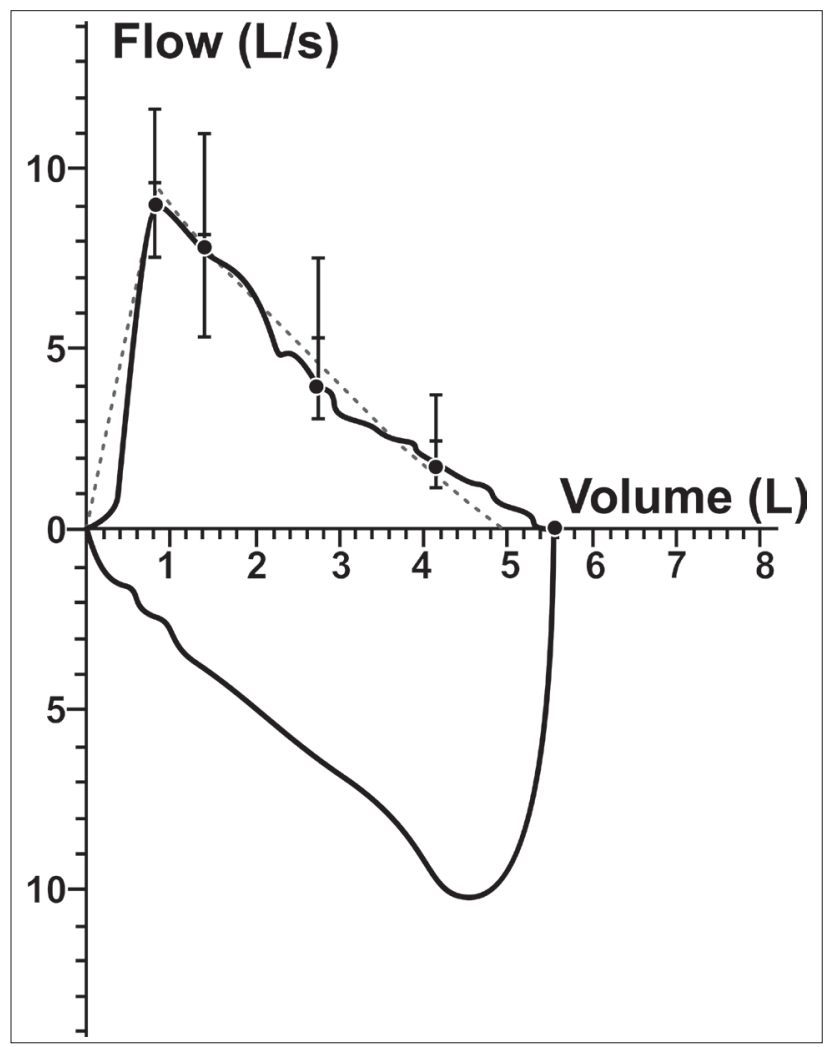

Fig. 5. Flow-volume curve with a late peak. Failure to demonstrate reproducibility will confirm these as submaximal efforts. 


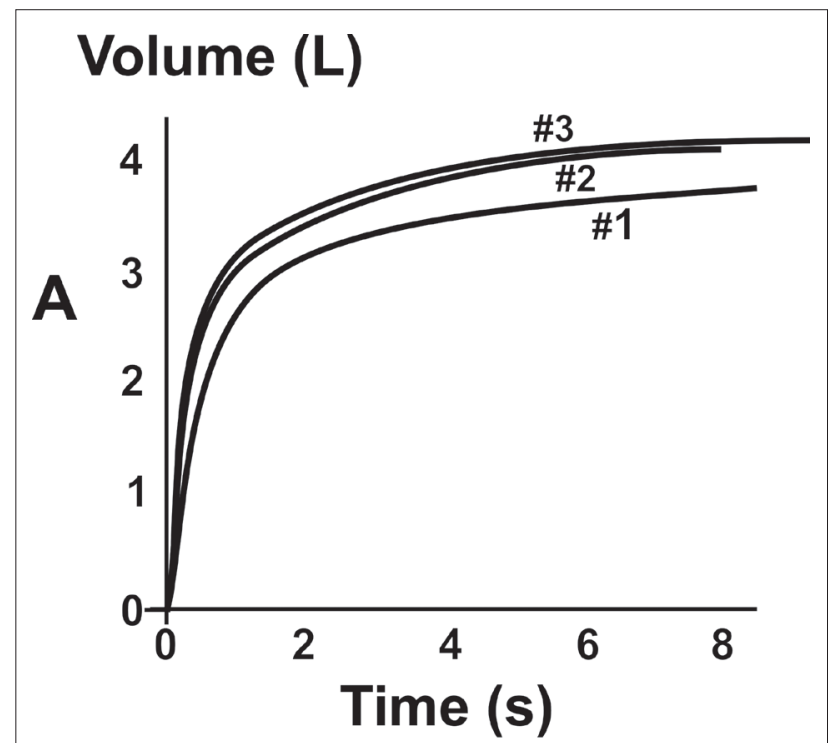

Flow (L/s)

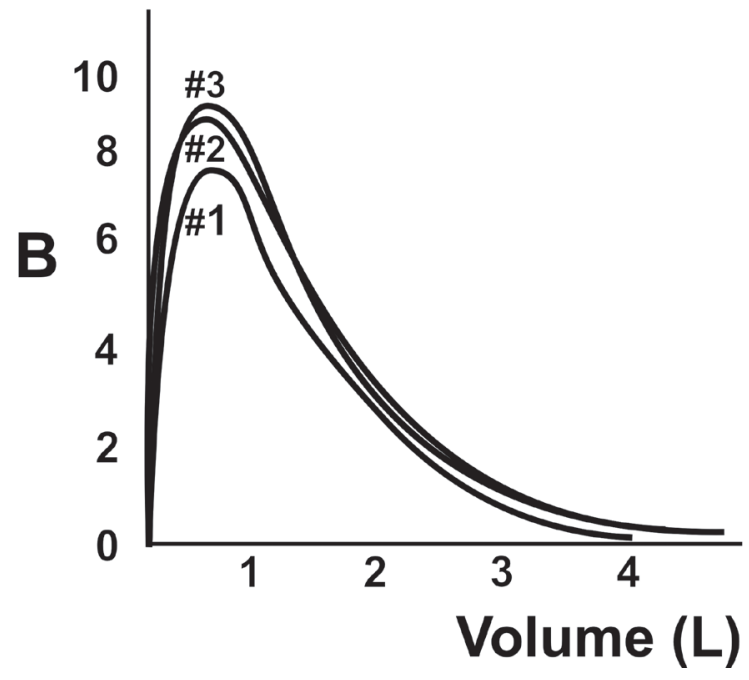

Fig. 6. A: Volume-time, and B: flow-volume curves, each demonstrating 3 acceptable forced vital capacity trials; but only \#2 and \#3 are reproducible as they are almost superimposable (adapted from Van Schalkwyk et al. ${ }^{2}$ ).

clinical decision). ${ }^{2,4}$ A standard bronchodilator test is performed as follows:

- The patient should abstain from using short-acting inhaled drugs at least 4 hours before testing. Long-acting bronchodilators and oral therapy with aminophylline should be stopped for 12 hours before the test. No smoking is allowed from one hour before testing and throughout the test procedure.

- Three acceptable tests of $\mathrm{FEV}_{1}, \mathrm{FVC}$ and PEF (of which 2 are repeatable) should be performed.

- A short-acting bronchodilator is administered. After a gentle expiration to FRC, a dose of $100 \mu \mathrm{g}$ of salbutamol (or equivalent) is inhaled in one breath to TLC. The breath is then held for $10 \mathrm{~s}$ before exhaling. Four separate doses (total dose $400 \mu \mathrm{g})$ are delivered at $30 \mathrm{~s}$ intervals. Ipratropium bromide (total dose 4 x $40=160 \mu \mathrm{g}$ ) can be used as an alternative.

- A waiting period of 10 - 15 minutes follows (30 minutes for ipratropium bromide).
- Three acceptable tests of $\mathrm{FEV}_{1}, \mathrm{FVC}$ and PEF (of which 2 are repeatable) must be performed.

- The best post-bronchodilator $\mathrm{FEV}_{1}$ and FVC are evaluated for improvement compared with the best pre-bronchodilator $\mathrm{FEV}_{1}$ and FVC. The percentage improvement in $\mathrm{FEV}_{1}$ can be calculated using the formula: $\left[\mathrm{FEV}_{1}\right.$ post-BD $-\mathrm{FEV}_{1}$ pre- $\mathrm{BD} / \mathrm{FEV}_{1}$ pre-BD] $\times 100$.

- A significant bronchodilator response is present if either the $\mathrm{FEV}_{1}$ or FVC improve by $200 \mathrm{ml}$ and $12 \%$. Reversibility may be complete (when the post-bronchodilator values improve to at least $80 \%$ of predicted) or partial (when the post-bronchodilator values improve to less than $80 \%$ of predicted).

\section{Interpretation and reporting of results}

Observed results should always be compared with an appropriate reference population, and expressed as percentage observed/predicted..$^{2-4}$ Predicted values for FVC and $\mathrm{FEV}_{1}$ are calculated from equations based on age, height and gender, as these parameters are the major determinants of lung and airway size in healthy individuals. ${ }^{17-19}$ Practically all office spirometers are programmed with many prediction equations derived from the study of Europeans. The European Community for Steel and Coal (ECSC, Table 5) equations are the most widely used. ${ }^{19}$

Most international guidelines for spirometry and the diagnosis and management of chronic respiratory conditions still advocate the use of $80 \%$ of predicted FVC and FEV, as suggested cut-off values, ${ }^{3-5,20}$ given the ease of calculation and interpretation. From a scientific perspective, however, the lower limit of normal (LLN) has a superior diagnostic accuracy. ${ }^{21-23}$

The use of inappropriate predicted values can result in a falsely increased rate of abnormal results in clinically normal people. Evidence suggests that southern African indigenous populations, compared with Europeans, show similar or higher $\mathrm{FEV}_{1} / \mathrm{FVC} \%$ and a lower FVC and $\mathrm{FEV}_{1}$ (up to 10\%), but it has also been suggested that socio-economic variables may explain these observations. ${ }^{2}$

In the past a correction factor of 0.9 for adjusting predicted values ( $\mathrm{FVC}$ and $\mathrm{FEV}_{1}$ ) was sometimes applied for black patients and those of Asian ancestry. ${ }^{2}$ In the absence of a large, all-inclusive study of the South African population, most local institutions currently use the European Community for Steel and Coal prediction equations without racial correction.

Local prediction equations are available (Table 6), but are rarely used, as they are not routinely included in the software packages of commercially available spirometers. Technically, however, these equations provide more accurate predicted values for screening for employment, compensation, surveillance and medico-legal purposes. ${ }^{2}$

The interpreting clinician should be aware of these considerations and decide on the most appropriate reference equations for their practice, and whether racial adjustment is necessary.

\subsection{Categorisation of spirometric results}

The major aims of interpreting spirometry are to confirm a clinical diagnosis and to estimate the severity of the disease. The initial assessment is based on a suggested algorithm (Fig. 7) that employs three variables: $\mathrm{FEV}_{1} / \mathrm{FVC} \%, \mathrm{FVC}$ (\% predicted) and $\mathrm{FEV}_{1}$ (\% predicted). Pattern recognition (see below) can also aid in this assessment. Many still advocate an $\mathrm{FEV}_{1} / \mathrm{FVC} \%$ of $<70 \%$ as indicative of obstruction, despite the fact that such a crude approach may lead to an underdiagnosis in young patients and an over-diagnosis in elderly patients. ${ }^{24}$ This can be avoided by ideally using the LLN (the lower 5 th percentile), particularly for screening purposes and in borderline cases. ${ }^{2}$

An obstructive ventilatory defect is defined as a disproportionate reduction in maximal airflow from the lung, with regard to the maximal volume that can be displaced from the lung. Per definition, the $\mathrm{FEV}_{1} / \mathrm{VC}$ 


\section{Guideline}

Table 5. European Community for Steel and Coal prediction equations (valid for ages 18 - 70 years)

\begin{tabular}{|c|c|c|c|c|}
\hline Gender & Parameter & Prediction equation & RSD & LLN \\
\hline \multirow[t]{3}{*}{ Male } & FVC (l) & $4.30 \mathrm{H}-0.029 \mathrm{~A}-2.49$ & 0.84 & \multirow{6}{*}{ Predicted value - (1.64 x RSD) } \\
\hline & $\mathrm{FEV}_{1}(\mathrm{l})$ & $5.76 \mathrm{H}-0.026 \mathrm{~A}-4.34$ & 1.00 & \\
\hline & $\mathrm{FEV}_{1} / \mathrm{VC}$ & $-0.18 \mathrm{~A}+87.21$ & 11.8 & \\
\hline \multirow[t]{3}{*}{ Female } & FVC (l) & $3.95 \mathrm{H}-0.025 \mathrm{~A}-2.60$ & 0.62 & \\
\hline & $\mathrm{FEV}_{1}(\mathrm{l})$ & $4.43 \mathrm{H}-0.026 \mathrm{~A}-2.89$ & 0.71 & \\
\hline & $\mathrm{FEV}_{\mathrm{I}} / \mathrm{VC}$ & $-0.19 A+89.10$ & 10.7 & \\
\hline
\end{tabular}

Table 6. Prediction equations for South African blacks

\begin{tabular}{lllll}
\hline Gender & Parameter & Prediction equation & RSD & LLN \\
\hline Male & FVC (l) & $2.9 \mathrm{H}-0.027 \mathrm{~A}-0.54$ & 0.75 & \\
& $\mathrm{FEV}_{1}(\mathrm{l})$ & $4.8 \mathrm{H}-0.024 \mathrm{~A}-3.08$ & 0.89 & Predicted value - (1.64 x RSD) \\
Female & $\mathrm{FVC}^{(1)}$ & $3.4 \mathrm{H}-0.028 \mathrm{~A}-1.87$ & 0.64 & 0.67 \\
& $\mathrm{FEV}_{1}(\mathrm{l})$ & $4.5 \mathrm{H}-0.023 \mathrm{~A}-3.04$ &
\end{tabular}

(Adapted from Louw et al. ${ }^{7}$ and Mokoetle et al..$^{10}$ )

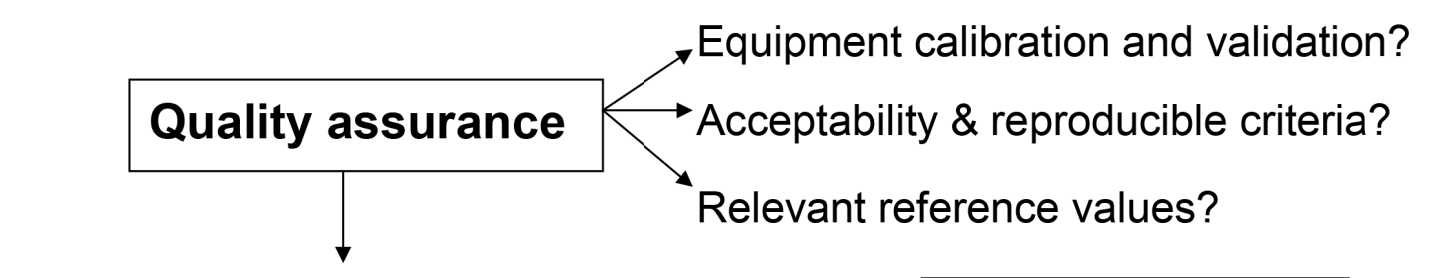

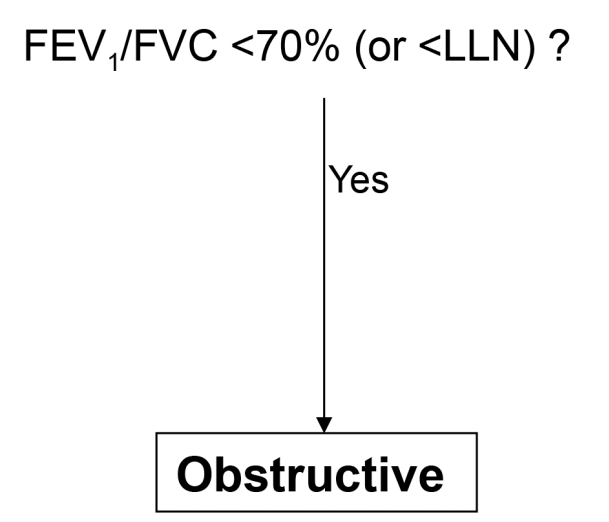

Alternative: Obstructive with reduced VC if FVC $<80 \%$ predicted

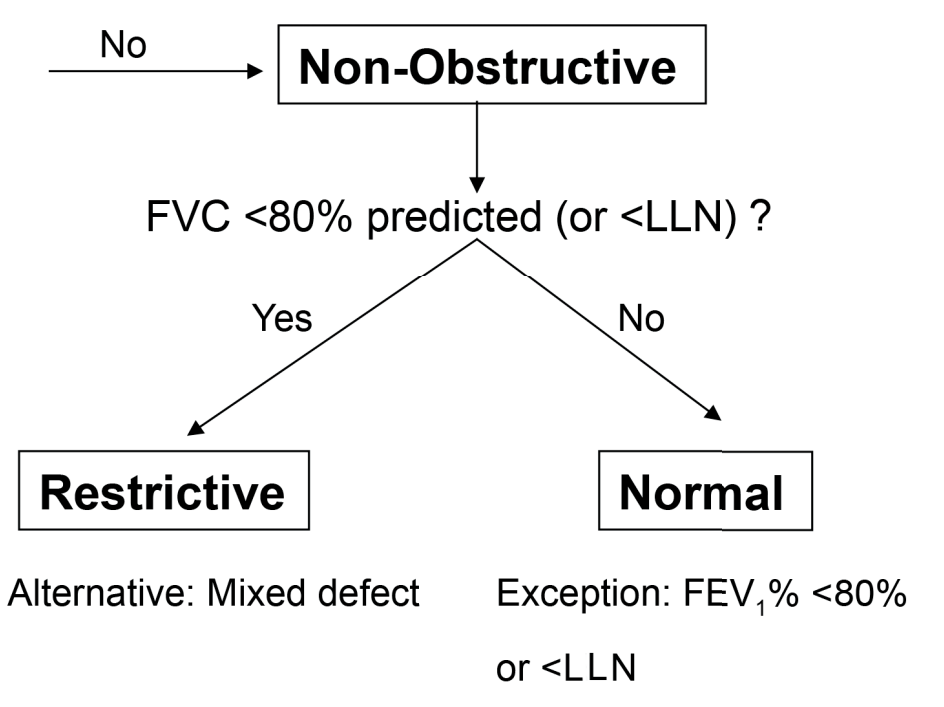

or $<$ LLN

\section{Grade impairment}

Fig. 7. An algorithm for the categorisation of spirometry. $L L N=$ lower limit of normal. 
is $<$ LLN (lower 5th percentile) ${ }^{2,6}$ The expiratory limb of the flow-volume loop appears concave (Fig. 8), as flow per volume is reduced. PEF is reduced, as is the $\mathrm{FEF}_{25-75 \%}$. FVC can be normal or reduced. Obstruction with reduced VC is most often due to air trapping, and the slow VC may be preserved in such cases. Moreover, plethysmography may then be indicated to evaluate the residual volume (RV), total lung capacity (TLC) and other parameters. A bronchodilator test should be performed in patients with an obstructive ventilatory defect, unless the indication for the test was purely screening, in which case the patient should be referred to a specialist.

A restrictive ventilatory defect is characterised physiologically by a reduction in TLC as determined by plethysmography (TLC per definition <lower 5th percentile), and can be inferred on spirometry when the $\mathrm{FEV}_{1} / \mathrm{FVC} \%$ is normal or high and the $\mathrm{FVC}$ is reduced (Fig. 9). Several conditions can reduce FVC, including pulmonary pathology (e.g. interstitial fibrosis), chest wall and pleural disease (e.g. large effusions) and neuromuscular diseases. Flow is often relatively preserved in cases with pulmonary pathology (due to an increased elastic recoil), but decreased in other causes. Restrictive impairments are often over-diagnosed, chiefly because of poor effort and inappropriate reference values.

Mixed obstructive-restrictive patterns are sometimes seen, as some diseases (e.g. bronchiectasis) may produce both, and some patients may have dual pathology (e.g. COPD and interstitial pulmonary fibrosis). Both the FEV,/VC and TLC should be <lower 5th percentile. It may be challenging to categorise a patient with a mixed pattern solely on the basis of spirometry, and to distinguish these cases from obstruction with reduced VC. Patients with mixed patterns should therefore be referred to a specialist centre for further investigations.

Variable and fixed large airway obstruction often gives rise to strikingly abnormal flow-volume loops. Fixed obstruction causes a so-called 'hamburger' pattern (Fig. 10). The inspiratory limb is flattened (horizontal) with variable extrathoracic obstruction, whereas the expiratory limb is flattened with variable intrathoracic obstruction.

\subsection{Grading}

Impaired lung functions are generally graded to quantify respiratory impairment/disability for medico-legal purposes, and to optimise and standardise treatment. ${ }^{2}$ Previously, lung functions were graded according to the worst-affected parameter (usually $\mathrm{FEV}_{1}$ for obstructive impairment and FVC for restrictive impairment). ${ }^{2}$ However, the ATS/ERS guidelines suggest grading both obstructive and restrictive ventilatory impairments solely according to $\mathrm{FEV}_{1}$, as there is little or no evidence for the use of FVC, VC or even TLC as a parameter of impairment. ${ }^{6}$ Where appropriate, post-bronchodilator FEV ${ }_{1}$ values should be used (Table 7). Large airway obstruction should not be graded according the $\mathrm{FEV}_{1}$.

Although spirometry is often sufficient for the evaluation of respiratory impairment, this is not always the case. Further investigations may be indicated (e.g. carbon monoxide diffusion capacity $\left(\mathrm{DL}_{\mathrm{CO}}\right)$ and/ or exercise testing), particularly in patients with clinical evidence of interstitial lung disease, or when a disproportionate degree of dyspnoea is present with a relatively preserved $\mathrm{FEV}_{1}$ and FVC.

\subsection{Reporting}

Spirometry reports must contain the following:

- subject name, and date and time of testing

- demographics (gender, age and race) and personal information (height and weight)

- origin of reference value (and whether or not a correction factor was used)

- latest calibration date

- numerical values and graphs in order to assess acceptability and repeatability

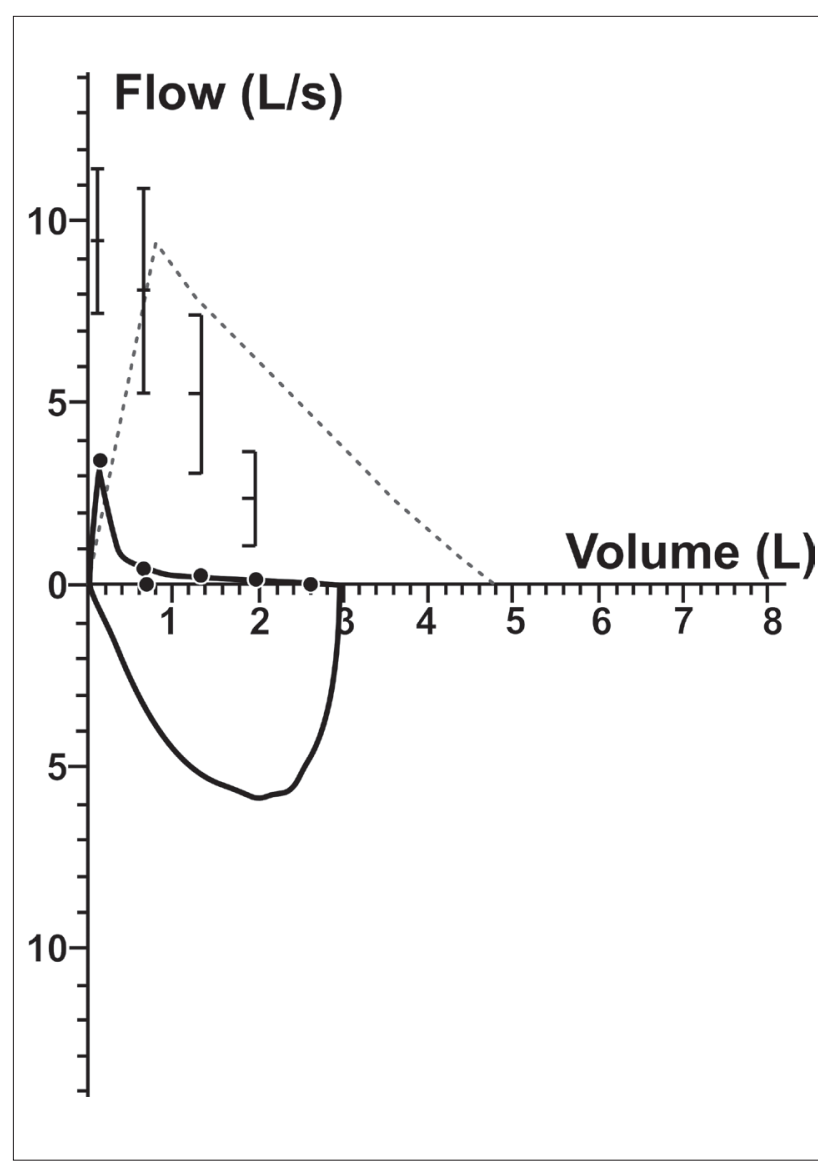

Fig. 8. Flow-volume curves exhibiting typical obstruction.

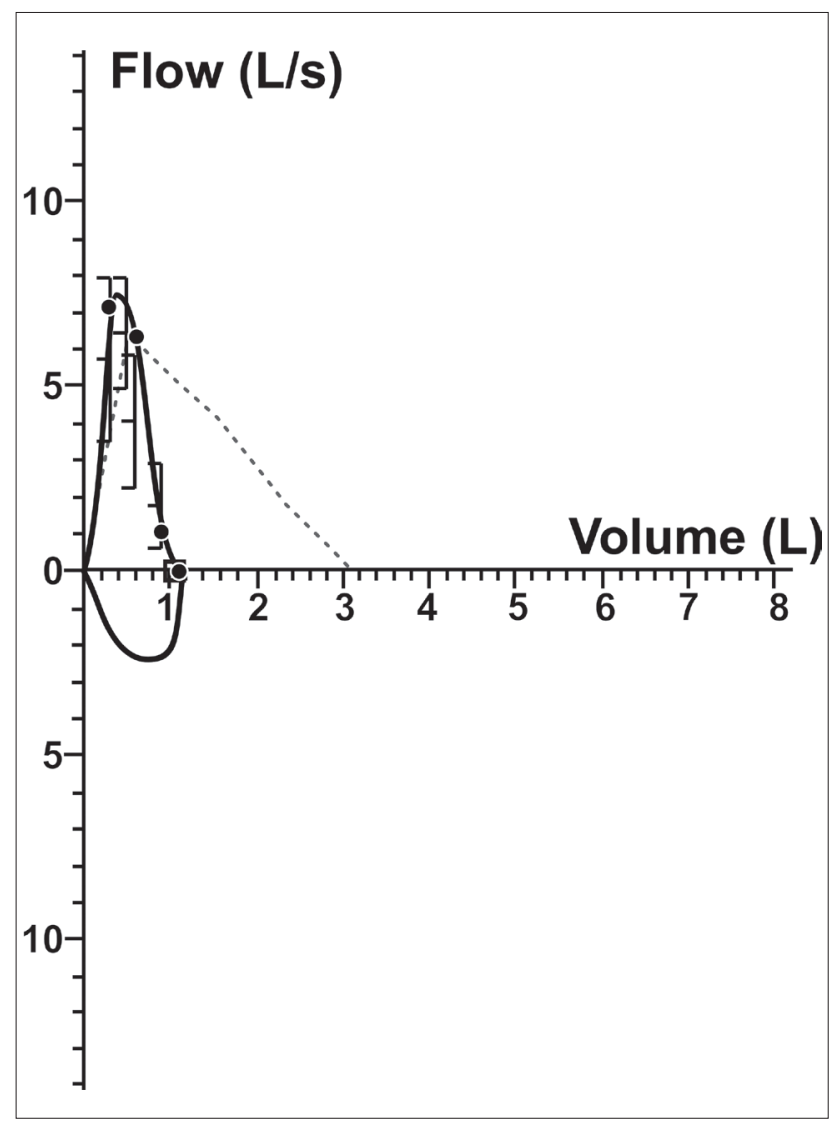

Fig. 9. Flow-volume curve exhibiting a typical restrictive pattern. 


\section{GuIdELINE}

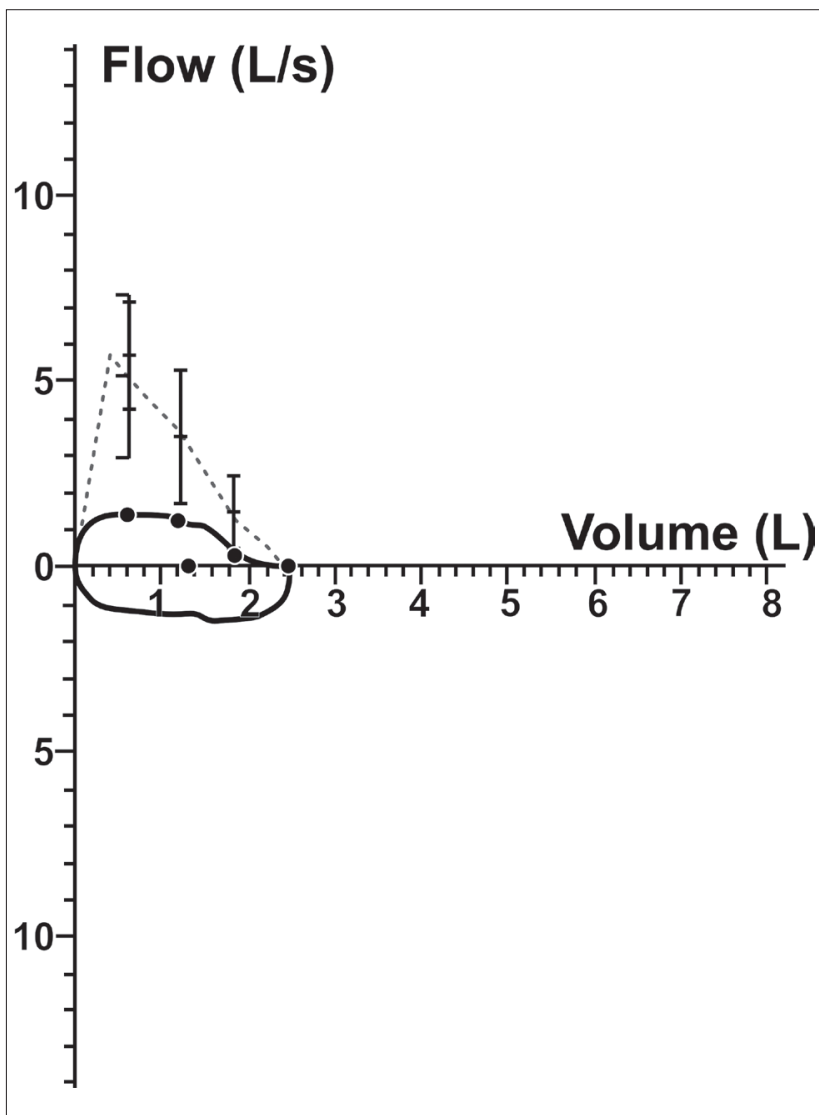

Fig. 10. Example of fixed large airway obstruction.

\begin{tabular}{ll}
\multicolumn{2}{l}{ Table 7. Severity of any spirometric abnormality based on FEV $_{1}^{*}$} \\
\hline Severity & FEV $_{1}(\%$ predicted $)$ \\
\hline Mild & $>70$ \\
Moderate & $60-69$ \\
Moderately severe & $50-59$ \\
Severe & $35-49$ \\
Very severe & $<35$ \\
${ }^{*}$ Adapted from Pellegrino et al. &
\end{tabular}

- basic interpretation (e.g. 'moderate obstructive ventilatory impairment with no reversibility').

Note that spirometry is often used to confirm clinical diagnoses, and to grade the impairment, but should never be viewed in isolation. The final assessment and interpretation of spirometry requires knowledge of medicine and the patient's full clinical details (e.g. to diagnose COPD), and may also require further special investigations (e.g. radiology, $\mathrm{DL}_{\mathrm{CO}}$ or plethysmography). Pulmonary function technologists and related personnel should therefore reserve the basic interpretation to the categorisation of abnormalities, and not comment on the presence or absence of a clinically relevant disease process.

\section{Spirometry training and certification \\ 9.1 Basic skills}

Operators must understand the principles of spirometry summarised in this statement, be able to calibrate the equipment, ensure optimal subject co-operation, provide acceptable and repeatable results, and categorise common abnormalities (taking relevant reference values into consideration).

\subsection{Personnel}

Pulmonary clinical technologists, general practitioners certified to practise occupational health, specialist physicians and pulmonologists are trained to perform basic spirometry. Pulmonary clinical technologists are competent to perform advanced lung function tests, which are best interpreted by qualified pulmonologists or specialist physicians with an interest in respiratory medicine.

The South African Thoracic Society (SATS) recognises the need to train other healthcare professionals (e.g. nurses) to perform basic spirometry, given the paucity of trained personnel, but cannot endorse the indiscriminate instruction to others. For further information on training opportunities and certification, contact: The Chairman, Spirometry and Training Certification Committee, South African Thoracic Society, PO Box 16433, Vlaeberg, 8018.

Acknowledgements. We thank other SATS council members for their assessment and approval of this manuscript, the pulmonary function technologists at Tygerberg Academic Hospital for providing the spirograms, and Carol Lochner, who complied all the figures.

\section{References}

1. Basson E, Stewart RS. The standards of spirometry in the RSA. S Afr Med J 1991;79(7):361-363.

2. Van Schalkwyk EM, Schults C, Joubert JR, White NW. Guideline for office spirometry in adults. S Afr Med J 2004;94(7 pt 2):576-587.

3iller MR, Crapo R, Hankinson J, et al. General considerations for lung function testing. Eur Respir J 2005;26:153-161. [http://dx.doi.org/10.1183/09031936.05.00034505]
2003

4. Miller MR, Hankinson J, Brusasco V, et al. Standardisation of spirometry. Eur Respir J 2005;26:319-338. Miller MR, Hankinson J, Brusasco V, et al. Stand

5. Wanger I, Clausen IL, Coates A, et al. Standardisation of the measurement of lung volumes. Eur Respir I 2005;26:511-522. [http://dx.doi.org/10.1183/09031936.05.00035005]

6. Pellegrino R, Viegi G, Brusasco V, et al. Interpretative strategies for lung function tests. Eur Respir

Pellegrino R, Viegi G, Brusasco V, et al. Interpretative strategies for
2005;26:948-968. [http://dx.doi.org/10.1183/09031936.05.00035205] Louw SJ, Goldin JG, Joubert G. Spirometry of healthy adult South African men. Part I. Normative values. S Afr Med J 1996;86(7):814-81

Goldin JG, Louw SJ, Joubert G. Spirometry of healthy adult South African men. Part II. Interrelationship between socio-environmental factors and 'race' as determinants of spirometry. S Afr Med J 1996;86 (7):820-826.

Hnizdo E, Churchyard G, Dowdeswell R. Lung function prediction equations derived from healthy South African gold miners. Occup Environ Med 2000;57:698-705.

Mokoetle K, De Beer M, Becklake MR. A respiratory survey in a black Johannesburg workforce. Thorax 1994;49:340-346. [http://dx.doi.org/10.1136/thx.49.4.34]

White N, Hanley JH, Lalloo UG, Becklake MR. Review and analysis of variation between spirometric values reported in 29 studies of healthy African adults. Am J Respir Crit Care Med 1994;150(2):348-355. 2. American Thoracic Society. Standardization of spirometry. Am Rev Respir Dis 1979;119:831-838.

3. Townsend MC. Spirometric forced expiratory volumes measured in the standing versus the sitting posture Am Rev Respir Dis 1984;130(1):123-12

4. Smith AA, Gaensler EA. Timing of forced expiratory volume in one second. Am Rev Respir Dis $1975 ; 112: 882-885$

5. Hankinson JL, Gardner RM. Standard waveforms for spirometer testing. Am Rev Respir Dis 1982;126(2):362-364

16. Hankinson JL, Bang KM. Acceptability and reproducibility criteria of the American Thoracic Society as observed in a sample of the general population. Am Rev Respir Dis 1991;143(3):516-521.

7. Hankinson JL, Kinsley KB, Wagner GR. Comparison of spirometric reference values for Caucasian and African American blue-collar workers. J Occup Environ Med 1996; 38(2):137-143.

18. Knudson RJ, Slatin RC, Lebowitz MD, Burrows B. The maximal expiratory flow-volume curve. Normal standards, variability and effects of age. Am Rev Respir Dis 1976;113(5):587-600.

19. Quanjer PH, Tammeling GJ, Cotes JE, et al. Lung volumes and forced ventilatory flows. Report Working Party Standardization of Lung Function Tests, European Community for Steel and Coal. Official Statement of the European Respiratory Society. Eur Respir J Suppl 1993;16:5-40.

20. Global Initiative for Chronic Obstructive Lung Disease. Spirometry for healthcare providers 2010 http://www.goldcopd.org/uploads/users/files/GOLD_Spirometry_2010.pdf (accessed 16 March 2012). 21. Levy ML, Quanjer PH, Booker R, Cooper BG, Holmes S, Small I. Diagnostic spirometry in primary care: Proposed standards for general practice compliant with American Thoracic Society and European Respiratory Society recommendations: a General Practice Airways Group (GPIAG) document, in association with the Association for Respiratory Technology \& Physiology (ARTP) and Education for Health. Prim Care Respir J 2009;18(3):130-147.

22. Levy ML, Quanjer PH, Booker R, Cooperd BG, Holmes S, Small I. Diagnostic spirometry in primary care: Proposed standards for general practice compliant with American Thoracic Society and European Respiratory Society recommendations. Prim Care Respir J 2009;18(3):130-147.

3. Miller MR, Quanjer PH, Swanney MP, Ruppel G, Enright PL. Interpreting lung function data using 80\% predicted and fixed thresholds misclassifies more than 20\% of patients. Chest 2011;139(1):52-59.

24. Quanjer PH, Hall GL, Stanojevic S, Cole TJ, Stocks J. Age- and height-based prediction bias in spirometry reference equations. Eur Respir J 2012;40(1):190-197. 